\title{
O PAPEL DE CHARCOT NA DOENÇA DE PARKINSON
}

\author{
HÉLIO A.G. TEIVE *
}

RESUMO - O autor apresenta breve revisão histórica acerca do papel desempenhado por J-M. Charcot, com a sua magistral contribuição na definição clínica da doença de Parkinson.

PALAVRAS-CHAVE: doença de Parkinson, J-M.Charcot, história da neurologia.

\section{The Charcot's contribution in the Parkinson's disease}

ABSTRACT - The author makes a short historical review about the seminal Charcot's contribution to the clinical definition of Parkinson's disease.

KEY WORDS: Parkinson's disease, J-M.Charcot, history of neurology.

"Para aprender a tratar uma doença, precisa-se aprender a reconhecê-la: o diagnóstico é o melhor trunfo no tratamento"

J-M. Charcot

A doença de Parkinson (DP) é um dos distúrbios do movimento mais encontrados na população idosa, representando até $2 / 3$ dos pacientes que visitam os grandes centros de distúrbios do movimento em todo o mundo. A prevalência da DP tem sido estimada entre 85 e 187 casos por 100000 pessoas e a incapacidade funcional produzida pela doença é comparável à causada pelos acidentes vasculares encefálicos ${ }^{1}$. O diagnóstico desta enfermidade neurodegenerativa é estabelecido basicamente pelo quadro clínico característico, sem a necessidade de utilização de exames complementares para tal. Os sintomas cardinais da DP são : tremor de repouso, bradicinesia, rigidez muscular e instabilidade postural. A presença de dois destes sinais acima descritos permite o diagnóstico de Parkinsonismo, sendo o Parkinsonismo Primário ou Idiopático (DP) a causa mais frequente. Outros autores acrescentam também os sinais como a postura fletida do pescoço, tronco e membros e a presença de bloqueio motor (freezing $)^{1,2}$.

\section{JAMES PARKINSON E A PARALISIA AGITANTE}

Coube a James Parkinson, médico inglês, membro do colégio real de cirurgiões, nascido em 1755 e falecido em 1824, o mérito da descrição inicial da doença que hoje leva o seu nome. James Parkinson publicou muitos artigos científicos dentro da área médica e nas áreas de geologia, paleontologia e sociologia, além de ter sido considerado um reformador social para o seu tempo e um panfletário político radical, escrevendo sob o pseudônimo de "Old Hubert"1-4. Em 1871, Parkinson publicou em Londres um ensaio intitulado "An Essay on the Shaking Palsy", que vem a ser a

Hospital de Clínicas (HC) da Universidade Federal do Paraná (UFPR), Curitiba: *Professor Assistente de Neurologia da UFPR, Coordenador do Ambulatório de Distúrbios do Movimento do HC-UFPR. Aceite: 17novembro-1997.

Dr. Hélio Teive - Praça Santos Andrade 37-A apto.112 - 80020-300 Curitiba PR - Brasil. 
primeira descrição mundial bem definida da DP. O ensaio continha 66 páginas, com cinco capítulos, em que o autor definiu de forma geral a doença, apresentou seis casos ilustrativos, determinou os sintomas principais, descreveu o diagnóstico diferencial com outras entidades e fez considerações a respeito da etiologia e também do tratamento. Dos seis casos clínicos apresentados, todos homens, com idades entre 50 e 72 anos, três foram examinados pessoalmente, dois foram encontrados casualmente na rua e avaliados depois e um dos casos não foi avaliado - "the lamented subject of which was only seen at a distance" $" 1-4$.

A enfermidade, intitulada "paralisia agitante", foi definida como doença caracterizada pela presença de movimentos involuntários tremulantes, com diminuição da força muscular, com tendência para a inclinação do tronco para frente e com alteração da marcha (festinação), tendo os sentidos e o intelecto não afetados. A evolução da doença foi caracterizada pela presença de tremores (principalmente das mãos e posteriormente mais difusos), com piora da marcha (passos curtos), quedas frequentes, obstipação, disartria, dificuldades para deglutição, sialorréia constante, incontinência urinária e finalmente anartria ${ }^{4}$. Parkinson, na sua clássica descrição, ainda interrogou a possibilidade da medula espinhal cervical, na junção com a medula oblonga, ser a possível sede da doença, secundariamente a traumatismos locais ${ }^{4}$. Apesar da publicação e da divulgação do ensaio sobre a paralisia agitante por Parkinson, a doença somente tornou-se bem conhecida pelos neurologistas na segunda metade do século $\mathrm{XIX}^{1-3}$. Vários outros neurologistas publicaram observações sobre a doença, então definida como paralisia agitante, entre eles Charcot $^{1-3}$. De todas as contribuições científicas no estudo da DP, após a descrição magistral de James Parkinson, sem sombra de dúvida a mais importante foi aquela realizada por Charcot.

\section{J-M. CHARCOT E A NEUROLOGIA}

Jean-Martin Charcot nasceu em Paris, em 29 de novembro de 1825, filho de um construtor de carruagens, e faleceu em 16 de agosto de 1893, aos 68 anos, já consagrado mundialmente como o pai da Neurologia, na província de Morvan, no interior da França ${ }^{5-7}$. As suas contribuições para a medicina, particularmente para a Neurologia, são de tamanha ordem, que se encontra sua influência marcante nas principais doenças neurológicas conhecidas. A neurologia, como sub-especialidade da medicina interna, teve seu grande impulso desenvolvimentista no Hospital La Salpêtrière, em Paris, no século dezenove, através dos estudos de Charcot e dos seus discípulos. Este hospital era na verdade, um grande asilo, com uma população de cerca de 5000 pacientes de todas as idades, geralmente portadores de doenças crônicas, incuráveis, de todos os tipos, particularmente do sistema nervoso ${ }^{3,5-7}$. Charcot descrevia o Hospital La Salpêtrière como o "grande asilo da miséria humana". Neste hospital, que foi um verdadeiro museu de enfermidades patológicas vivas, Charcot e sua equipe estudaram e definiram inúmeras doenças neurológicas, retirando-as do obscurantismo vigente na época. Entre as influências que Charcot teve na sua formação acadêmica devem-se citar as de Duchenne de Boulogne (que ele considerava o seu grande mestre em Neurologia), do professor Rayer (que o ajudou sobremaneira na carreira médica), de E.F. Vulpian (íntimo amigo e colaborador científico) e também do neurologista inglês J.H. Jackson, por quem Charcot tinha grande admiraçãa ${ }^{5-7}$. A ascensão científica de Charcot na França, posteriormente em toda a Europa e finalmente em todo o mundo, coincidiu com uma época de grande progresso econômico, político e sócio-cultural da sociedade francesa $a^{6}$.

Charcot, considerado o primeiro professor de doenças do sistema nervoso no mundo, tinha uma fabulosa memória visual e gostava particularmente de desenhar os pacientes que examinava (posturas anormais, sinais) e pode descrever inúmeras doenças neurológicas graças ao chamado método anátomo-clínico (avaliação clínica meticulosa dos pacientes e posterior correlação com os estudos de necrópsia $)^{3,5-8}$. Tornaram-se nesta época mundialmente famosas, e repletas de assistentes de todas as partes do mundo, as aulas do professor Charcot com discussão de casos clínicos, feitas de improviso, às terças-feiras, no Hospital La Salpêtrière, conhecidas como "Leçons du mardi à la Salpêtrière" $5-8$. Nesta época, Charcot era conhecido como o "César da Salpêtrière", em face do seu 
temperamento austero, reservado, quase taciturno, bem como da sua autoridade férrea e da sua liderança entre os seu pares ${ }^{5-7}$. Entre os vários e famosos discípulos de Charcot podem-se citar os nomes de Bouchard (que posteriormente tornou-se seu desafeto e inimigo na carreira acadêmica), Joffroy, Debove, Raymond, Brissaud, Pierre Marie, Pitrè, Bourneville, Gilles de la Tourette, Babinski, Guinon, Souques e Meige ${ }^{5-7}$. Com relação aos inúmeros médicos e neurologistas estrangeiros que estagiaram sob a supervisão de Charcot, deve-se lembrar os nomes de Bechterew, Darkschewitch, Kojewnikow, Marinesco, Sachs e Sigmund Freud ${ }^{5-7}$. Charcot foi o responsável pela definição de vários sinais semiológicos em neurologia, sendo os mais importantes os seguintes : a caracterização dos diferentes tipos de distúrbios urinários de causa neurológica, a artropatia de causa neurogênica (conhecida como "articulação de Charcot"), a síndrome piramidal, a semiologia do corno anterior, a prosopagnosia e os sinais clínicos da doença de Parkinson, entre outros ${ }^{5-7}$. Em relação à descrição de doenças neurológicas, podem-se citar, de forma resumida, as seguintes contribuições magistrais de Charcot : a descrição da esclerose lateral amiotrófica (conhecida como doença de Charcot), a esclerose múltipla (definida por Charcot e Vulpian como esclerose em placas), a artropatia tabética, a doença de Charcot-Marie-Tooth, a claudicação intermitente, os estudos de localização cerebral e de doenças da medula espinhal (com a sistematização dos tratos e fascículos da medula espinhal), a patogênese da hemorragia cerebral (através da descrição dos microaneurismas de Charcot-Bouchard), os estudos sobre afasias, sífilis, paralisia facial, epilepsia (em particular a clássica descrição dos automatismos deambulatórios), e finalmente os estudos sobre a histeria (histeroepilepsia) e sobre hipnose ${ }^{5-7}$. Estas últimas contribuições científicas de Charcot foram alvo de muita discussão e de críticas entre seus contemporâneos, motivando inúmeras polêmicas envolvendo o nome de Charcot, inclusive colocando sob suspeita o caráter científico dos seus estudos na época ${ }^{5-7}$. A utilização do método de hipnotismo no tratamento de pacientes histéricos foi definido por seu colaborador e discípulo, Pierre Marie, como um "leve ponto fraco" do grande mestre

Com relação aos distúbios do movimento, Charcot teve participação decisiva na descrição de várias enfermidades tanto hipocinéticas, como a doença de Parkinson, como hipercinéticas, como por exemplo os tiques e a síndrome de Tourette, além de contribuir com opiniões e idéias em outras enfermidades como as ataxias locomotoras (em especial a ataxia de Friedreich), as coréias (de Huntington e de Sydenham) e as síndromes agora definidas sob o nome "startle"- síndromes do susto exagerado" (franceses saltitantes do Maine, Latah, Myriachti) ${ }^{3,5-7}$.

Deve-se ressaltar também que Charcot iniciou em seu serviço, no Hospital La Salpêtrière, a documentação fotográfica dos pacientes com várias enfermidades neurológicas, as quais foram posteriormente publicadas na "Iconographie Photographique de la Salpêtrière". Este procedimento antecedeu em muitos anos a filmagem de pacientes com distúrbios do movimento, que nos dias atuais permite melhor análise e estudo dos diferentes tipos de movimentos anormais ${ }^{6}$.

\section{CHARCOT E A DOENÇA DE PARKINSON}

A contribuição de Charcot ao estudo da paralisia agitante foi de tamanha monta que seria muito justo que o seu nome tivesse sido acrescentado ao de Parkinson na nomeação da doença. Em primeiro lugar, foi Charcot que sugeriu a mudança do nome da enfermidade, de paralisia agitante para doença de Parkinson ("la maladie de Parkinson”), em homenagem à descrição clássica de James Parkinson. Por outro lado, Charcot acrescentou várias contribuições pessoais na descrição do quadro clínico, definindo a presença dos chamados quatro sinais cardinais da doença, quais sejam tremor, lentidão do movimento (bradicinesia), rigidez e dificuldades do equilíbrio, apresentando critérios para o diagnóstico diferencial e também sugerindo o primeiro tratamento para a doença $\mathrm{a}^{2,3,5,6,9}$ (Quadro 1).

$\mathrm{Na}$ época em que Charcot traçou a história natural da DP, não havia ainda idéia da origem desta enfermidade, que ele definia como uma nevrose, termo utilizado na época para as doenças que não apresentavam uma lesão própria no sistema nervoso. Contudo, a degeneração da substância negra do mesencéfalo foi posteriormente descrita por Tretiakoff, na sua tese realizada sob supervisão de Pierre Marie, um dos discípulos preferidos de Charcot $^{2,3}$. 
Quadro 1. Contribuições de Charcot na doença de Parkinson.

- Denominação doença de Parkinson

- Caracterização do tremor de repouso (mãos)

- Definição da rigidez muscular

- Definição da instabilidade postural e da bradicinesia

- Demonstração da ausência de fraqueza muscular

- Caracterização da facies, postura, presença de disartria, disfagia, micrografia e alterações autonômicas

- Primeiro tratamento farmacológico

Charcot definiu a presença do tremor como um sintoma cardinal, referindo-se ao início unilateral, geralmente em um membro superior (demonstrando o tremor característico das mãos), observando-se durante o período de repouso e posteriormente tornando-se generalizado. Realizou estudos comparativos, diferenciando o tremor parkinsoniano dos tremores de outras etiologias, como o da esclerose múltipla (do tipo cerebelar) e o chamado tremor senil. Neste sentido Charcot utilizou um esfigmógrafo (que era utilizado para registrar o pulso arterial) adaptado, para a avaliação e registro dos tremores ao nível do punho. Ele classificou o tremor parkinsoniano como do tipo lento, com 4-6 oscilações por segundo. Outra característica definida por Charcot, quanto ao tremor da doença de Parkinson, foi o acometimento muito raro da cabeça. Esta definição de Charcot provocou na época, inúmeros debates (com opiniões contrárias às dele, definindo a presença de tremor cefálico na DP), motivando inclusive a Charcot a realização de uma apresentação clínica em seu anfiteatro, com vários pacientes portadores de tremores de cabeça, tronco e membros, definindo aqueles que eram portadores da DP e aqueles que não eram ${ }^{1-3,5,6,9-11}$. Charcot também definiu a presença da alteração da postura, com a atitude peculiar do corpo e dos membros, como olhar fixo,e as características de imobilidade, e tendência a propulsão e retropulsão. Neste particular Charcot descreveu uma manobra, hoje tradicional, para a avaliação da instabilidade postural: “... se eu puxar os ombros do paciente para trás, ocorrerá uma retropulsão..." ${ }^{, 3,5,69}$. Charcot descreveu também as fácies características dos pacientes com DP, “em máscara”: “..os músculos da face ficam imóveis, com um olhar fixo peculiar, produzindo uma expressão de tristeza, indiferença e mesmo de estupidez....." ${ }_{3,5,6,9}$. A escrita peculiar dos pacientes, com micrografia, bem como a disartria e hipofonia características também foram salientadas.Outra característica de extrema importância na doença de Parkinson, definida por Charcot, e que não havia sido descrita por Parkinson, foi a presença de rigidez muscular, a nível do pescoço, tronco e das extremidades.A presença do sinal da roda denteada não foi observado por Charcot (o que motivou comentários dos seus detratores de que ele apenas se preocupava com a história clínica e não tocava nos pacientes - o exame físico neurológico dos pacientes seria realizado pelos seus assistentes!), tendo sido descrito somente em 1911, por Harold N. Moyer, sendo considerado por ele um excelente sinal diagnóstico precoce da DP. Charcot enfatizou a diferença da rigidez com a espasticidade, acrescentando a ausência de hiperreflexia profunda na rigidez $z^{1,2,5,6,8-11}$.

A presença de fraqueza muscular foi contestada por Charcot, relacionando este erro cometido por Parkinson à presença de rigidez muscular. “... a fraqueza muscular é decorrente da rigidez que prevalece nos músculos...”; “... Existe uma lentidão na execução do movimento, antes do que uma verdadeira fraqueza muscular...”. Outro conceito discutido por Charcot foi o da bradicinesia. Ele concluiu que esta era independente da rigidez e da presença dos tremores: "Apesar do tremor, o paciente é capaz de fazer muitas coisas, porém as realiza com notável lentidão" "2,5,6,8,9. Charcot também discordou da descrição original de Parkinson, quanto a preservação das funções corticais superiores na doença. Ele considerou a presença de perda de memória e enfim de uma disfunção cognitiva, fatos estes hoje bastante conhecidos ${ }^{2,5,6,8,9}$.

Charcot também descreveu presença de acatisia na DP, e também a presença de disfunção autonômica. A presença de acatisia (um conceito discutível) foi demonstrada entre os pacientes com DP, principalmente no período noturno. Associado a sensação de inquietude ou desejo de mover-se, 
foi referido também a presença de sensações de tensão muscular, fadiga corporal e sensação de que o paciente estivesse carregando um peso sobre si. A presença de excessiva sensação de calor, associada a sudorese intensa, foi também detalhada nos pacientes com $\mathrm{DP}^{5,9}$. Quanto à causa mortis mais frequente na doença de Parkinson, Charcot citou a infecção pulmonar, que já havia sido notada e descrita por Trousseau.

Finalmente, Charcot foi o primeiro neurologista a sugerir uma terapêutica para a doença de Parkinson. Em 1877, ele indicou como tratamento um precursor dos alcalóides da beladona, a hioscinamida, que é uma substância com propriedades anticolinérgicas. Outros métodos de tratamento definidos por Charcot, sem sucesso, foram a utilização de uma cadeira vibratória - "trepidant"(pelo fato dos pacientes referirem melhora do seu quadro clínico após longas viagens de carruagem ou trem) e de um aparelho especial que suspendia os paciente no ar, com a utilização de uma armadura. Alguns dos pacientes descritos por Charcot apresentaram, na sua evolução, melhora clínica ou cura, e poder-se-ia interrogar da existência de parkinsonismo secundário (por drogas por exemplo) nestes pacientes $^{1-3,5,6,9-11}$.

As contribuições de Charcot à neurologia ("Pai da Neurologia"), aos distúrbios do movimento (precursor do estudo dos distúrbios do movimento) e particularmente no estudo da DP (colaborador importante na descrição da doença) são de grande relevância científica e merecem ser relembradas nos dias de hoje, quando começamos a vivenciar a neurologia moderna.

\section{REFERÊNCIAS}

1. Teive HAG, Meneses MS. Histórico. In Meneses MS, Teive, HAG. Doença de Parkinson: aspectos clínicos e cirúrgicos. Rio de Janeiro: Guanabara Koogan, 1996,:4-14.

2. Pearce JMS. Parkinson's disease and its management. Oxford: Oxford Univ Press, 1992:4-12.

3. Finger S. Origins of neuroscience: a history of explorations into brain function.New York: Oxford Univ Press, 1994:223-228.

4. Parkinson J. An essay on the shaking palsy. London: Whittingham \& Rowland, 1817.

5. Goetz CG. Charcot: the clinician. the tuesday lessons. New York: Raven Press, 1987:123-140.

6. Goetz CG, Bonduelle M, Gelfand T. Charcot: constructing neurology. New York: Oxford Univ Press, 1995:113-120.

7. Guillain G. J.-M. Charcot: his life-his work. New York: Paul B. Hoeber, 1959.

8. Goetz CG. Jean-Martin Charcot and Silas Weir Mitchell. Neurology 1997;48:1128-1132.

9. Charcot JM. De la paralysie agitante. Cinquième leçon. In Charcot JM. Leçons sur les maladies du système nerveux faites à la Salpetrière. Paris: Adrien Delahaye et E. Lecrosnier Éditeurs, 1880: Tome 1er.

10. Teive HAG. Charcot redivivo. O Dendrito. Boletim Oficial da Sociedade Paranaense de Ciências Neurológicas: 1995;1:6-7.

11. Teive HAG. Charcot e os distúrbios do movimento. Striatum. (Boletim Oficial do Grupo de Trabalho em Distúrbios do Movimento da Academia Brasileira de Neurologia 1997); 1:3-4. 